\title{
PENGARUH PENDIDIKAN KESEHATAN TERHADAP UPAYA PENCEGAHAN DIABETES MELLITUS GESTASIONAL PADA IBU HAMIL DI PUSKESMAS TAMALANREA JAYA KOTA MAKASSAR
}

\author{
Andi Hasliani ${ }^{1,}$ Rahmawati $^{2}$ \\ ${ }^{1}$ STIKES Nani Hasanuddin Makassar \\ ${ }^{2}$ STIKES Nani Hasanuddin Makassar \\ Alamat korespondensi : (andihasliani@stikesnh.ac.id)
}

\begin{abstract}
ABSTRAK
Diabetes mellitus gestasional menjadi masalah kesehatan masyarakat sebab penyakit ini berdampak langsung pada kesehatan ibu dan janin. Dampak yang ditimbulkan oleh ibu penderita diabetes melitus gestasional adalah ibu berisiko tinggi terjadi penambahan berat badan berlebih, terjadinya preklamsia, eklamsia, bedah sesar, dan komplikasi kardiovaskuler hingga kematian ibu. Pendidikan kesehatan dilakukan pada ibu hamil untuk meningkatkan pengetahuan dan diharapkan ada upaya yang dilakukan untuk mencegah penyakit tersebut. Tujuan penelitian ini adalah untuk mengetahui pengaruh pendidikan kesehatan terhadap upaya pencegahan diabetes mellitus gestasional di Puskesmas Kapasa Kota Makassar. Penelitian ini menggunakan jenis penelitian kuantitatif dengan studi desain quasi ekspriment dengan pendekatan the one group pretest-posttest design. Data yang terkumpul diolah dan dianalisis dengan menggunakan program computer dengan uji $t$ berpasangan atau uji wilcoxon dengan tingkat kemaknaan $\alpha=0,05$. Penelitian ini akan dilaksanakan di Wilayah Kerja Puskesmas Kapasa Kota Makassar pada bulan Februari sampai Agustus Tahun 2019. Populasi dalam penelitian ini adalah ibu hamil yang berada di wilayah kerja Puskesmas Kapasa dan terdata di rekam medik, teknik sampling menggunakan accidental sampling sehingga besaran sampel tidak ditentukan. Hasil penelitian menunjukkan ada hubungan yang signifikan antara upaya pencegahan diabetes mellitus gestasional sebelum dan sesudah dilakukan pendidikan kesehatan dengan nilai $P$ Value : 0,000 lebih kecil dari nilai $\alpha=0,05$. Kesimpulan dari penelitian ini adalah ada pengaruh pendidikan kesehatan pada ibu hamil trimester I terhadap upaya pencegahan diabetes mellitus gestasional di Puskesmas Tamalanrea Jaya Kota Makassar.
\end{abstract}

\section{Kata Kunci : Pendidikan Kesehatan, DM Gestasional, Faktor Risiko}

\section{PENDAHULUAN}

Transisi pola penyakit dalam beberapa dasawarsa ini telah bergeser dari penyakit infeksi menular ke penyakit tidak menular atau penyakit degenaratif. Hingga saat ini penyakit degeneratif telah menjadi penyebab kematian terbesar di dunia. Bahkan hal ini berimbas kepada kerugian yang telah dialami oleh beberapa negara di dunia. Sebanyak 38 juta $(68 \%)$ dari 56 juta kematian di dunia pada tahun 2012 disebabkan oleh penyakit degeneratif (WHO, 2014).

Pergeseran pola penyakit ini juga terjadi di Indonesia, di mana penyakit degeneratif telah mengalami peningkatan. Penyakit degeneratif merupakan penyakit tidak menular yang berlangsung kronis seperti penyakit jantung, hipertensi, diabetes, kegemukan dan lainnya. Saat ini Indonesia menanggung beban ganda penyakit di bidang kesehatan, yaitu penyakit infeksi yang masih merajalela ditambah lagi dengan berbagai penyakit kronik degeneratif (Handajani et al., 2010). Penyakit degeneratif ini kemungkinan akan terus berkembang seiring dengan kemajuan zaman dan kesejahteraan masyarakat..

Angka kejadian Diabetes Mellitus (DM) di dunia dari tahun ke tahun terus meningkat, data terakhir dari World Health Organization (WHO) menunjukkan pada tahun 2000 sebanyak 150 juta penduduk dunia menderita DM dan angka ini akan menjadi dua kali lipat pada tahun 2025. Peningkatan angka penderita penyakit ini akan terjadi di negara berkembang karena pertumbuhan populasi, penuaan, diet yang tidak sehat, obesitas dan kurang aktivitas fisik. Di Indonesia, menurut data Riset Kesehatan Dasar 2013 didapatkan proporsi kejadian DM sebesar $6,9 \%$ pada penduduk usia $\geq 15$ tahun.

Diabetes Melitus Gestasional (DMG) adalah suatu gangguan toleransi karbohidrat yang terjadi atau diketahui pertama kali pada saat kehamilan sedang berlangsung. Keadaan ini biasa terjadi pada saat 24 minggu usia kehamilan dan sebagian kadar glukosa darah penderita akan kembali normal setelah melahirkan (Depkes RI, 2008). Namun, pada 
hampir setengah angka kejadiannya, diabetes akan muncul kembali (Nurrahmani, 2012).

Diabetes melitus gestasional terjadi sekitar 4\% dari semua kehamilan di Amerika Serikat, dan 3-5\% di Inggris (ADA, 2004). Prevalensi diabetes melitus gestasional di Eropa sebesar 2-6\% (Buckley et al, 2001). Prevalensi prediabetes di Indonesia pada tahun 2007 sebesar $10 \%$ sedangkan prevalensi diabetes melitus gestasional di Indonesia sebesar $1,9 \%-3,6 \%$ pada kehamilan umumnya (Soewardono dan Pramono, 2011). Pada ibu hamil dengan riwayat keluarga diabetes melitus, prevalensi diabetes gestasional sebesar 5,1\% (Maryunani, 2008). Angka ini lebih rendah dari pada prevalensi di Negara Ingris dan Amerika Serikat. Meskipun demikian, masalah diabetes gestasional di Indonesia masih membutuhkan penanganan yang serius melihat jumlah penderita yang cukup banyak serta dampak yang ditimbulkan pada ibu hamil dan janin.

Diabetes mellitus gestasional menjadi masalah kesehatan masyarakat sebab penyakit ini berdampak langsung pada kesehatan ibu dan janin (Osgood et al, 2011). Dampak yang ditimbulkan oleh ibu penderita diabetes melitus gestasional adalah ibu berisiko tinggi terjadi penambahan berat badan berlebih, terjadinya preklamsia, eklamsia, bedah sesar, dan komplikasi kardiovaskuler hingga kematian ibu. Setelah persalinan terjadi, maka penderita berisiko berlanjut terkena diabetes tipe 2 atau terjadi diabetes gestasional yang berulang pada 3 masa yang akan datang. Sedangkan bayi yang lahir dari ibu yang mengalami diabetes gestasional berisiko tinggi untuk terkena makrosomia, trauma kelahiran. Selain itu, bayi berisiko tinggi untuk terkena hipoglikemia, hipokalsemia, hiperbilirubinemia, sindrom gangguan pernafasan, polistemia, obesitas dan diabetes melitus tipe 2 (Perkins et al, 2007).

Berdasarkan data yang diperoleh di Puskesmas Kapasa Kota Makassar ibu hamil dengan faktor risiko diabetes mellitus gestasional cukup tinggi. Tahun 2018 tercatat 6 ibu hamil mengalami diabetes gestasional dan 3 ibu hamil mengalami pregestasional diabetes.

\section{BAHAN DAN METODE}

\section{Lokasi, Populasi dan Sampe}

Penelitian ini menggunakan jenis penelitian kuantitatif dengan studi desain quasi ekspriment dengan pendekatan the one group pretest-posttest design. Dalam model penelitian quasi ekspriment ini tidak digunakan suatu pembatasan-pembatasan yang sangat ketat terhadap keharusan randomisasi atau acak.

Tes awal dilakukan untuk mengetahui pengetahuan ibu hamil tentang diabetes mellitus gestasional secara umum dan upaya pencegahan diabetes mellitus gestasional. Selanjutnya akan diberikan perlakuan berupa pendidikan kesehatan tentang diabetes mellitus gestasional secara umum dan upaya pencegahan diabetes mellitus gestasional. Tes akhir dilakukan untuk perubahan perilaku ibu hamil dalam upaya mencegah diabetes mellitus gestasional

Penelitian ini akan dilaksanakan di Wilayah Kerja Puskesmas Kapasa Kecamatan Tamalanrea Kota Makassar pada bulan Februari sampai Agustus Tahun 2019

Populasi dalam penelitian ini adalah ibu hamil yang berada di wilayah kerja Puskesmas dan terdata di rekam medik, sedangkan sampel yang diambil hanya ibu hamil dengan factor risiko diabetes mellitus gestasional. Teknik sampling menggunakan accidental sampling sehingga besaran sampel tidak ditentukan

\section{Analisa Data}

Data yang terkumpul selama penelitian akan peneliti olah menggunakan software pengolah data. Data akan dimasukkan, diolah dan hasil analisis akan dilihat secara langsung. Analisa data menggunakan analisa univariat dan bivariat. Analisa univariat disajikan dalam tabel distribusi frekuensi, sedangkan analisa bivariat yaitu untuk mengetahui pengaruh pendidikan kesehatan terhadap upaya pencegahan diabetes mellitus gestasional menggunakan uji $\mathrm{T}$ berpasangan jika memenuhi syarat atau uji Wilcoxon sebagai alterantif ketika data tidak memenuhi syarat

\section{HASIL PENELITIAN}

1. Analisis Univariat

Tabel 1. Distribusi Frekuensi Responden Berdasarkan di Puskesmas Tamalanrea Jaya Kota Makassar.

\begin{tabular}{|l|c|c|}
\hline Frekuensi Responden & $\mathrm{n}$ & $\%$ \\
\hline Umur & 18 & 60,0 \\
<20 dan > 35 Tahun & 12 & 40,0 \\
20-35 Tahun & 15 & 50,0 \\
\hline Pendidikan & 7 & 23,3 \\
Rendah & 8 & 26,7 \\
Menengah & & \\
Tinggi & 2 & 6,7 \\
\hline Pekerjaan & 22 & 73,3 \\
\hline Wiraswasta & 6 & 20,0 \\
\hline IRT & & \\
\hline PNS & &
\end{tabular}

Berdasarkan tabel 1 diperoleh data responden yang berumur $<20$ Tahun dan > 35 Tahun sebanyak 18 responden $(60 \%)$ 
dan yang berumur $20-35$ tahun sebanyak 12 responden (40\%). Data responden berpendidikan rendah sebanyak 15 responden $(50,0 \%)$, berpendidikan menengah 7 responden $(23,3 \%)$ dan yang berpendidikan tinggi sebanya 8 responden $(26,7 \%)$. Data responden dengan pekerjaan Wiraswasta sebanyak 2 responden $(6,7 \%)$, pekerjaan IRT sebanyak 22 responden $(73,3 \%)$ dan pekerjaan PNS sebanyak 6 responden $(20,0 \%)$.

Tabel 2. Distribusi Frekuensi Responden Berdasarkan upaya pencegahan diabetes mellitus gestasional sebelum dilakukan pendidikan kesehatan di Puskesmas Tamalanrea Jaya Kota Makassar.

\begin{tabular}{|c|c|c|}
\hline Pekerjaan & $\mathrm{n}$ & $\%$ \\
\hline Baik & 0 & 0,0 \\
\hline Cukup & 6 & 20,0 \\
\hline Kurang & 24 & 80,0 \\
\hline Total & 30 & 100 \\
\hline
\end{tabular}

Berdasarkan tabel 2. diperoleh data responden sebelum diberikan pendidikan kesehatan, yang melakukan upaya pencegahan diabetes mellitus yang baik sebanyak 0 responden $(0,0 \%)$, cukup sebanyak 6 responden $(20 \%)$ dan yang kurang sebanyak 24 Responden (80\%).

Tabel 3. Distribusi Frekuensi Responden Berdasarkan upaya pencegahan diabetes mellitus gestasional setelah dilakukan pendidikan kesehatan di Puskesmas Tamalanrea Jaya Kota Makassar.

\begin{tabular}{|c|c|c|}
\hline Pekerjaan & $\mathrm{n}$ & $\%$ \\
\hline Baik & 7 & 23,3 \\
\hline Cukup & 20 & 66,7 \\
\hline Kurang & 3 & 10,0 \\
\hline Total & 50 & 100 \\
\hline
\end{tabular}

Berdasarkan tabel 3. diperoleh data responden setelah diberikan pendidikan kesehatan, yang melakukan upaya pencegahan diabetes mellitus yang baik sebanyak 7 responden $(23,3 \%)$, cukup sebanyak 20 responden $(66,7 \%)$ dan yang kurang sebanyak 3 Responden (10,0\%).

2. Analisis Bivariat

Tabel 4. Uji Normalitas Data.

Sebelum dilakukan uji statistik untuk menjawab hipotesis maka harus dilakukan uji normalitas data untuk menentukan jenis uji yang digunakan.

\begin{tabular}{|l|l|c|c|c|c|c|}
\hline & \multicolumn{3}{|l|}{$\begin{array}{l}\text { Kolmogorov- } \\
\text { smirnov }\end{array}$} & \multicolumn{3}{l|}{ Shapiro Wilk } \\
\cline { 2 - 7 } & Statistic & df & Sig & Statistic & df & Sig \\
\hline Pretest & .128 & 30 & .200 & .933 & 30 & .580 \\
\hline Postest & .143 & 30 & .119 & .939 & 30 & .840 \\
\hline
\end{tabular}

Berdasarkan tabel 4. di atas, diperoleh hasil nilai $\mathrm{P}$-Value untuk kedua kelompok data adalah $>0,05$ dengan demikian dapat disimpulkan bahwa distribusi kedua kelompok data adalah normal sehingga uji yang digunakan adalah uji t berpasangan.

Tabel 5. pengaruh pendidikan kesehatan terhadap pencegahan preeclampsia.

\begin{tabular}{|l|c|c|c|}
\hline & $\mathrm{t}$ & $\mathrm{df}$ & $\begin{array}{c}\text { Sig. (2- } \\
\text { tailed) }\end{array}$ \\
\hline $\begin{array}{l}\text { Pretest } \\
\text { pencegahan } \\
\text { diabetes } \\
\text { mellitus - } \\
\text { posttest } \\
\text { pencegahan } \\
\text { diabetes } \\
\text { mellitus }\end{array}$ & 10.265 & 29 & .000 \\
\hline
\end{tabular}

Berdasarkan tabel 5 didapatkan data pengaruh pendidikan kesehatan terhadap pencegahan pre post diabetes gestasional dengan uji statistik uji $t$ berpasangan diperoleh nilai $\rho=0,000$ jika di bandingkan dengan nilai $\alpha=0,05$, maka $\rho<\alpha$. Hal tersebut menunjukkan bahwa terdapat pengaruh yang signifikan pemberian pendidikan kesehatan pada terhadap upaya pencegahan diabetes mellitus pada ibu hamil di Puskesmas Tamalanrea Jaya Kota Makassar.

\section{PEMBAHASAN}

Hasil penelitian yang dilakukan menunjukkan ada pengaruh yang signifikan pendidikan kesehatan terhadap upaya pencegahan diabetes mellitus getasional pada ibu hamil, hal ini dapat dilihat dari hasil uji $t$ berpasangan pada upaya yang dilakukan sebelum dan sesudah pedidikan kesehatan dengan $p$ Value 0,000 lebih kecil dari nilai $\alpha$ : 0,05 .

Sebelum dilakukan pendidikan kesehatan, terlebih dahulu dilakukan pengukuran upaya-uapaya yang telah dilakukan ibu hamil untuk mencegah diabetes mellitus gestasional, hasil dari pengukuran yang dilakukan ternyata upaya yang dilakukan ibu hamil untuk mencegah diabetes mellitus gestasional masih sangat rendah. Pendidikan kesehatan diberikan kepada ibu hamil untuk meningkatkan upaya pencegahan diabetes mellitus gestasional, dan pengukuran yang dilakukan 2 bulan setelah pemberian pendidikan kesehatan menunjukkan ada peningkatan upaya yang dilakukan ibu hamil untuk mencegah diabetes mellitus gestasional. 
Penelitian ini sejalan dengan yang dilakukan oleh Dharmastuti (2016), ada penagruh pendidikan kesehatan terhadap upaya pencegahan hipoglikemia pada penderita DM di RSUD dr. Moewardi Surakarta, ada peningkatan pengetahuan yang signifikan sebelum dan sesudah pemberian pendidikan kesehatan.

Hasil penelitian tersebut sesuai dengan teori bahwa salah satu penatalaksanaan DM adalah pendidikan kesehatan terutama tentang komplikasi DM. Pendidikan Kesehatan adalah upaya untuk mempengaruhi dan atau mempengaruhi orang lain, baik individu, kelompok, atau masyarakat, agar melaksanakan perilaku hidup sehat. Sedangkan secara operasional, pendidikan kesehatan merupakan suatu kegiatan untuk memberikan atau meningkatkan pengetahuan, sikap dan praktik masyarakat dalam memelihara dan meningkatkan kesehatan mereka sendiri.

Pemberian pendidikan kesehatan pada ibu hamil dapat meningkatkan upaya yang dilakukan untuk mencegah diabetes mellitus gestasional. Upaya-upaya yang dilakukan tersebut adalah mengurangi makan-makanan manis, menjaga jumlah asupan makanan terutama ketika trisemester ketiga kehamilan agar berat badan tidak bertambah, akan tetapi ibu hamil tidak boleh sampai kekurangan makanan dan berolahraga dengan teratur serta melakukan aktivitas fisik dari mulai yang ringan hingga sedang sehingga kalori yang tidak diperlukan dalam tubuh akan terbakar dengan sendirinya.

\section{KESIMPULAN}

1. Upaya yang dilakukan untuk mencegah preeclampsia sebelum diberikan pendidikan kesehatan sebagian besar adalah kurang sejumlah 24 responden $(80.0 \%)$ dari 30 responden pada ibu hamil di Puskesmas Tamalanrea Jaya Kota Makassar.

2. Upaya yang dilakukan untuk mencegah preeclampsia sesudah diberikan pensisikan kesehatan sebagian besar adalah pengetahuan dengan nilai cukup sejumlah 20 responden $(66.7 \%)$ dari 30 responden pada ibu hamil di Puskesmas Tamalanrea Jaya Kota Makassar.

3. Terdapat perbedaan signifikansi sebelum dan sesudah diberikan pendidikan kesehatan tentang pencegahan diabetes mellitus, maka dapat disimpulkan bahwa ada pengaruh pendidikan kesehatan terhadap upaya pencegahan diabetes mellitus gestasional pada ibu hamil di Puskesmas Tamalanrea Jaya Kota Makassar

\section{SARAN}

1. Bagi Pasien

Pendidikan kesehatan tentang pencegahan diabetes mellitus gestasional dapat dijadikan sebagai infomasi dan preventif bagi ibu hamil terutama untuk meningkatkan status kesehatan, mempertahankan derajat kesehatan yang sudah ada, memaksimalkan fungsi dan peran ibu hamil, serta membantu ibu hamil untuk mengatasi masalah kesehatan khususnya pencegahan diabetes mellitus.

2. Bagi Bidan Puskesmas Tamalanrea Jaya

Diharapkan dengan penelitian ini mampu menambah pengetahuan dan mengidentifikasi pasien yang beresiko tinggi terjadi diabetes mellitus gestasional, harus mengidentifikasi tentang pola hidup, pola makan, memotivasi ibu hamil untuk rutin mengontrol kadar gula darah.

\section{DAFTAR PUSTAKA}

A. Aziz Alimul Hidayat. 2007. Riset Keperawatan dan Teknik Penulisan IImiah. Salemba Medika: Surabaya

A. Wawan dan Dewi. 2011. Teori dan Pengukuran, Sikap dan Perilaku Manusia. Nuha Medika: Yogyakarta

WHO. (2014). Diabetes Melitus. WHO News: Fact Sheets. Diakses dari: http://www.who.int/mediacentre/factshe ets/fs138/en/ pada tanggal 1 April 2014. 2. Depkes RI. (2013).

Riset Kesehatan Dasar (RISKESDAS) 2013. Jakarta: Badan Penelitian dan Pengembangan Kesehatan.

Feryanto FA. 2011. Asuhan Kebidanan Ptologis. Jakarta : Salemba Medika

Kusnanto, P. (1999). Diabetes Mellitus Gestasional dengan tinjauan faktorfaktor risiko diabetes mellitus gestasional di rumah sakit umum pusat dokter kariadi semarang. Laporan Penelitian Akhir. Universitas Diponegoro 
Pamolango, M.A., Wantouw, B., Sambeka, J. (2013). Hubungan Riwayat Diabetes Mellitus pada Keluarga dengan Kejadian Diabetes Mellitus Gestasional pada Ibu Hamil di PKM Bahu Kec. Malalayang Kota Manado. Ejournal keperawatan (e-Kp) Volume 1, Nomor 1, Agustus 2013.

Hermanto. 2012. Korelasi antara HOMA-IR Ibu Diabetes Mellitus Gestasional Trimester Tiga dengan Luaran Maternal dan Neonatal.

Pusat Data dan Informasi Kementrian Kesehatan RI. 2013. Situasi dan Analisis Diabetes.

Riset Kesehatan Dasar (RISKESDAS) 2017. Jakarta: Badan Penelitian dan Pengembangan Kesehatan

WHO. (2014). Diabetes Melitus. WHO News: Fact Sheets. Diakses dari: http://www.who.int/mediacentre/factshe ets/fs138/en/ pada tanggal 1 April 2014. 2. Depkes RI. (2013). 